\footnotetext{
Abiy S. Kebede ${ }^{1,2^{*}}$, Robert J. Nicholls ${ }^{3,2}$, Derek Clarke ${ }^{2}$, Cristina Savin ${ }^{4}$, Paula A. Harrison ${ }^{5,6}$

${ }^{1}$ Department of Civil and Environmental Engineering, Brunel University London, Uxbridge UB8 3PH, UK

${ }^{2}$ School of Engineering, University of Southampton, Southampton SO16 7QF, UK

${ }^{3}$ Tyndall Centre for Climate Change Research, University of East Anglia, Norwich NR4 7TJ, UK

${ }^{4}$ TIAMASG Foundation, Sfintii Voievozi 6, 010963 Bucharest, Romania

${ }^{5}$ Centre for Ecology \& Hydrology, Lancaster Environment Centre, Lancaster LA1 4AP, UK

${ }^{6}$ Environmental Change Institute, University of Oxford, Oxford OX1 3QY, UK

${ }^{+}$Corresponding author-Email: Abiy.Kebede@brunel.ac.uk; Tel: +44 (0) 1895268183
}

\title{
Manuscript
}

Accepted for publication in the journal of:

Science of the Total Environment

January 2021 


\section{Integrated Assessment of the Food-Water-Land-Ecosystems Nexus in Europe: Implications for Sustainability}

\section{Abstract}

Climate and socio-economic change impacts are likely to cross traditional sectoral and regional boundaries with cascading indirect, and potentially far-reaching, repercussions. This is particularly important for the food-water-land-ecosystems (FWLE) nexus, which is fundamental for the achievement of at least six of the seventeen Sustainable Development Goals (SDGs). A holistic understanding of the FWLE nexus interactions and how and to what extent various exogenous drivers of change affect them is therefore central to cross-sectoral adaptation planning. Here, we present such an integrated assessment for Europe applying a regional Integrated Assessment Platform (IAP). The study explores a wide range of future climate and socio-economic scenarios using more than 900 model simulations. The results show that food production is likely to be the main driver of Europe's future landscape change dynamics (with or without climate change). Agriculture and land use allocation is often driven by complex cross-sectoral interactions with cascading effects on other sectors such as forestry, biodiversity, and water under the various scenarios. The modelling also highlighted that while sustaining current levels of food production at the European level could be achievable under most climate and socio-economic scenarios, there are significant regional differences with winners and losers. The analysis raises the question of whether current production and consumption policies are sustainable in the long-term. Such systematic integrated model-based analysis plays a crucial role in informing development of cross-sectoral policies that maximise synergies and minimise trade-offs across nexus sectors, regions, and scenarios. This is essential to achieve the SDGs.

Key Words: Food-water-land-ecosystems nexus; climate and socio-economic change; cross-sectoral impacts; integrated assessment; sustainability; Sustainable Development Goals (SDGs)

\section{Introduction}

The world has strong aspirations to achieve the Sustainable Development Goals (SDGs) of the United Nations' 2030 Sustainable Development Agenda (e.g., Le Blanc 2015). However, the potential conflicts and trade-offs between the various nexus sectors that underpin the different SDGs are less explored (e.g., Allen et al. 2018; Nilsson et al. 2018). In Europe, the use of land- and water-based resources are increasingly constrained with challenges for maintaining production (e.g., agricultural and forest goods) to a point where their capacity to meet current and future consumption demands may be threatened (e.g., FAO 2011; Holman et al. 2017; Kluts et al. 2017; van Vliet et al. 2013). In addition, agricultural and other land use changes have important implications for biodiversity (e.g., effects of fertiliser and pesticides; Geiger et al. 2010; Henle et al. 2008; Rounsevell et al. 2006). These risks are further exacerbated by less-sustainable production practices (e.g., intensification and/or abandonment of farming), increasing socio-economic pressures, and climate change. Sustainable use and management of these resources and robust, long-term climate change adaptation policy decisions require a better understanding of the linkages and inter-dependencies between the various system components (e.g., Bleischwitz et al. 2018; Liu et al. 2018; Rasul 2016). This is particularly important for the food-water-landecosystems (FWLE) nexus, which is fundamental for at least six of the seventeen SDGs. These include: SDG2: Zero Hunger, e.g., sustainable food production; SDG6: Clean Water and Sanitation, e.g., improving water-use efficiency; SDG11: Sustainable Cities and Communities, e.g., sustainable urbanisation; SDG12: Responsible Consumption and Production, e.g., sustainable use and management of natural resources; SDG13: Climate Action, e.g., impacts reduction and adaptation to climate change; SDG15: Life on Land, e.g., reducing loss of biodiversity.

Analysis of sustainability issues is inherently multi-dimensional and interconnected across the three pillars of sustainable development: (i) social, (ii) economic, and (iii) environmental (Giddings et al. 2002; Lozana 2008). Important environmental (e.g., climate change) and socio-economic (e.g., technological, demographic) trends underlie these issues (e.g., UN 2013), trends that are expected to continue through this century and beyond (O'Neill et al. 2014; van Vuuren et al. 2011). There are also potential synergies 
and conflicts within and between the SDGs, which are not widely discussed (e.g., Hutton et al. 2018; Yamagata et al. 2018). A holistic understanding of the FWLE nexus interactions and how these change under potential futures is, hence, key to identifying synergies and harmful trade-offs between food, water and land use systems, and, in turn, the long-term health and productive potential of ecosystems that provide important services and support biodiversity and livelihoods (e.g., Albrecht et al. 2018). This is crucial to informing development of cross-sectoral policies and achieving the SDGs in Europe and more widely.

Previous studies have assessed these issues either qualitatively or quantitatively using a limited number of scenarios and sectors, potentially ignoring important drivers and uncertainties, and the resulting complex cross-sectoral interactions (e.g., Schweizer and Kurniawan 2016). Ideally, quantitative assessment of sustainability issues should consider diverse plausible futures across scales within modelbased "multidimensional exploratory scenarios" (e.g., Lord et al. 2016) and applied across the range of multiple sectors representing the nexus system (e.g., Harrison et al. 2015a,b, 2016; Jacob et al. 2018; Wachsmuth 2015). Systems integration and nexus-based approaches offer this ability (e.g., Bazilian et al. 2011; Liu et al. 2015, 2018). Such approaches allow identification of key co-benefits and potential conflicts between multiple sectors as well as endogenously simulating socio-environmental impacts under various drivers of change (e.g., Albrecht et al. 2018; Hoff 2011; Howells and Rogner 2014; RomeroLankao et al. 2017; Stafford-Smith et al. 2017; UN 2015; 2017). They can also inform the development of robust, cross-sectoral policies under uncertain futures (e.g., Jäger et al. 2015; Reilly and Willenbockel 2010; Swart et al. 2004; van Vuuren et al. 2014). In this paper, we apply such a modelling framework, a regional integrated assessment platform (IAP) of Europe (Harrison et al. 2015a), to assess the complex FWLE nexus interactions and associated key implications for sustainability. The study explores more than 900 stylised scenarios of key climatic and socio-economic change driver combinations sampling a wide range of uncertainty.

\section{Method and Materials}

Quantitative assessment of multiple-sector interactions and associated impacts of multiple drivers of change requires application of integrated analytical approaches and models (e.g., Allen et al. 2018). Liu et al. (2018) suggested that a nexus-based modelling approach in principle should involve five key steps: (i) formulate nexus research goals, (ii) define system(s) of interest, (iii) develop conceptual framework, (iv) analyse relationships, and (v) simulate dynamics. This procedure involves key choices in terms of selecting representative impact metrics, identifying key drivers of change (both climatic and nonclimatic), considering the wider uncertainty space and associated plausibility of future scenarios, and assessing key impacts across sectors, scales, and scenarios.

In this study, a regional integrated assessment model, the CLIMSAVE IAP ${ }^{1}$, is applied to explore Europewide and regional area-averaged projections, as well as spatial variability, of future impacts across the FWLE nexus. The IAP is an interactive and freely available web-based platform that allows users to quantitatively assess climate change impacts, vulnerability and adaptation considering various climate and socio-economic scenarios. It integrates a number of meta-models (Holman and Harrison 2012) representing six key land- and water-based sectors, namely, agriculture (Audsley et al. 2015), biodiversity (Harrison et al. 2006), fluvial and coastal flooding (Mokrech et al. 2015), forestry (Morales et al. 2005), urban development (Reginster and Rounsevell 2006), and water resources (Wimmer et al. 2015). This study focuses on seven impact indicators (Table 1 ) that represent key nexus interactions and associated impacts across the six sectors.

Table 1: Selected nexus impact indicators.

\begin{tabular}{|l|l|l|l|}
\hline & Indicators & Indicator Description & Brief Model and Data Description \\
\hline 1 & $\begin{array}{l}\text { Food } \\
\text { production }\end{array}$ & $\begin{array}{l}\text { Measure of food } \\
\text { productivity of land based } \\
\text { on total food (or feed) } \\
\text { produced as crops or }\end{array}$ & $\begin{array}{l}\text { A mechanistic farm-based optimizing linear programming of long- } \\
\text { term strategic agricultural land use and soil/climate clustering } \\
\text { approach is used to simulate food production. The modelling is } \\
\text { based on the relative profitability of crops and trees and demand }\end{array}$ \\
\hline
\end{tabular}

\footnotetext{
${ }^{1}$ Refers to the Integrated Assessment Platform developed by the CLIMSAVE (CLimate change Integrated assessment Methodology for cross-Sectoral Adaptation and Vulnerability in Europe) project (www.climsave.eu; see Harrison et al. 2013, 2015a).
} 


\begin{tabular}{|c|c|c|c|}
\hline & & $\begin{array}{l}\text { livestock in terms of their } \\
\text { metabolisable energy. }\end{array}$ & $\begin{array}{l}\text { for food/feed to determine the most profitable land use (Audsley } \\
\text { et al. 2015). The study focuses on twelve crop types: winter and } \\
\text { spring wheat, winter and spring barley, winter oil seed rape, } \\
\text { potatoes, grain maize, sunflower, soybean, cotton, grass, and } \\
\text { olives. The soil input data is based on the European soil database }{ }^{2}- \\
\text { a total of } 580 \text { distinct soils are identified using a clustering } \\
\text { procedure considering factors such as available water capacity and } \\
\text { eliminating no soil (urban) or very shallow soil types (bare rock) } \\
\text { based on CORINE database }{ }^{3} \text { ). The climate input data (monthly } \\
\text { precipitation, temperatures, evapotranspiration, radiation and } \\
\text { wind) is based on Dubrovsky et al. (2015). }\end{array}$ \\
\hline 2 & $\begin{array}{l}\text { People } \\
\text { flooded }\end{array}$ & $\begin{array}{l}\text { Number of people } \\
\text { flooded by a 1-in-100 } \\
\text { year event due to both } \\
\text { coastal and fluvial } \\
\text { flooding }\end{array}$ & $\begin{array}{l}\text { The number of people flooded is simulated by combining estimates } \\
\text { of the areas at risk of flooding based on topography and relative } \\
\text { sea-level rise and change in peak river flow and indicative level of } \\
\text { protection of flood defences and population distribution within } \\
\text { these areas (see Mokrech et al. 2015). Key datasets used include: } \\
\text { land cover map (CORINE dataset), elevation data (ESRI SRTM data), } \\
\text { population density and GDP (EUROSTAT NUTS data }{ }^{4} \text { ), extreme sea } \\
\text { levels and land uplift/subsidence (DIVA database; Vafeidis et al. } \\
\text { 2008), and simulated fluvial flood maps (based on Feyen et al. } \\
\text { 2012). }\end{array}$ \\
\hline 3 & $\begin{array}{l}\text { Water } \\
\text { exploitation } \\
\text { index }\end{array}$ & $\begin{array}{l}\text { Dimensionless ratio of } \\
\text { annual water withdrawals } \\
\text { for agricultural, } \\
\text { domestic/industrial, } \\
\text { environmental and } \\
\text { cooling use to water } \\
\text { availability from } \\
\text { renewable resources }\end{array}$ & $\begin{array}{l}\text { The water meta-model uses look-up tables to emulate the } \\
\text { performance and reproduce the outputs of the original } \\
\text { WaterGAP3 }{ }^{5} \text { (Water-Global Assessment and Prognosis) model on } \\
\text { hydrology and water use (see Wimmer et al. 2015). The simulation } \\
\text { takes into account simultaneous changes in temperature and } \\
\text { precipitation to estimate water availability. The amount and } \\
\text { relative changes in water use (withdrawal and consumption for the } \\
\text { domestic, manufacturing and electricity sectors) are estimated } \\
\text { considering country level factors such as population, GDP, } \\
\text { production of thermal electricity, gross values added from } \\
\text { manufacturing, and water efficiency measures due to behavioural } \\
\text { and technological changes. The agriculture model simulates } \\
\text { agricultural water use. }\end{array}$ \\
\hline 4 & $\begin{array}{l}\text { Artificial } \\
\text { surfaces }\end{array}$ & $\begin{array}{l}\text { Mean percentage } \\
\text { changes in residential and } \\
\text { non-residential areas }\end{array}$ & $\begin{array}{l}\text { The change in the proportion of artificial surfaces is simulated as a } \\
\text { function of changes in socio-economic variables (population, GDP } \\
\text { per capita) and societal values (strictness of planning constraints to } \\
\text { limit sprawl, household preferences for proximity to green spaces, } \\
\text { social amenities, attractiveness of the coast in terms of scenic } \\
\text { values or flood risk) (Reginster and Rounsevell 2006). The baseline } \\
\text { estimates are based on the area of residential and non-residential } \\
\text { properties from CORINE land cover data }{ }^{3} \text {. }\end{array}$ \\
\hline 5 & $\begin{array}{l}\text { Land use } \\
\text { diversity }\end{array}$ & $\begin{array}{l}\text { Representation of multi- } \\
\text { functionality of the } \\
\text { landscape based on } \\
\text { Shannon Index, for land } \\
\text { uses such as urban, } \\
\text { intensive arable, } \\
\text { intensive grass, extensive } \\
\text { grass, forest and others }\end{array}$ & $\begin{array}{l}\text { The Shannon Index metric is estimated based on outputs of the } \\
\text { rural land use allocation and urban models with areas of the six } \\
\text { land uses considered to represent the indicator (e.g., Dunford et al. } \\
\text { 2015). }\end{array}$ \\
\hline 6 & $\begin{array}{l}\text { Biodiversity } \\
\text { vulnerability } \\
\text { index }\end{array}$ & $\begin{array}{l}\text { Dimensionless metric } \\
\text { representing changes in } \\
\text { climate and habitat } \\
\text { suitability for twelve } \\
\text { representative species } \\
\text { covering a range of flora } \\
\text { and fauna from different } \\
\text { habitats and regions }\end{array}$ & $\begin{array}{l}\text { The biodiversity meta-model is used to simulate the suitable } \\
\text { climate space of a large number of species selected to interact with } \\
\text { other sectors/sub-systems such as agriculture, forestry, coastal and } \\
\text { water, and to indicate a range of associated ecosystem services. } \\
\text { The simulation is based on ensembles of ANNs and incorporates } \\
\text { bioclimatic variables, i.e., climate (temperature, precipitation, solar } \\
\text { radiation and wind speed) and soil moisture (available water } \\
\text { holding capacity), to characterise bioclimatic suitability envelops } \\
\text { for providing projections of species' distributions. Harrison et al. } \\
\text { (2006) provides detailed description baseline data, including } \\
\text { observed species' distributions (e.g., published literature for }\end{array}$ \\
\hline
\end{tabular}




\begin{tabular}{|c|c|c|c|}
\hline & & & insects and mammals, European Bird Census Council for birds). \\
\hline 7 & $\begin{array}{l}\text { Timber } \\
\text { production }\end{array}$ & $\begin{array}{l}\text { Total timber produced } \\
\text { based on the modelled } \\
\text { timber productivity of } \\
\text { five }^{x} \text { representative } \\
\text { European tree species } \\
\text { within areas of modelled } \\
\text { profitable managed } \\
\text { forest }\end{array}$ & $\begin{array}{l}\text { The impacts of climate change on forest ecosystem services (e.g., } \\
\text { wood production, wood balance) and the benefits of forest } \\
\text { management are simulated using the meta-model that emulates } \\
\text { the performance of the original GOTILWA+ (Growth Of Trees Is } \\
\text { Limited by WAter) model (see Morales et al. (2005); Sallaba et al. } \\
\text { (2015) for detailed model and data descriptions). }\end{array}$ \\
\hline \multicolumn{4}{|c|}{$\begin{array}{l}\text { 'These are: (1) Common poppy (Papaver rhoeas), (2) Linnet (Carduelis cannabina), (3) Bilberry (Vaccinium myrtillus), (4) Hornbeam } \\
\text { (Carpinus betulus), (5) Norway spruce (Picea abies), (6) Brown bear (Ursus arctos arctos), (7) Western dappled white butterfly (Euchloe } \\
\text { crameri), (8) Common saltmarsh grass (Puccinellia maritima), (9) Strawberry clover (Trifolium fragiferum), (10) Bell heather (Erica cinerea), } \\
\text { (11) Red deer (Cervus elaphas), \& (12) Capercaillie (Tetrao urogallus). The above list of species group is selected from the total of } 111 \\
\text { species (included in the SPECIES model that has been trained and validated for all species) to represent a cross-section of species from } \\
\text { different taxa, habitats, and regions in Europe. } \\
{ }^{\times} \text {These are: (1) Pinus sy/vestris, (2) Pinus halepensis, (3) Pinus pinaster, (4) Quercus ilex, and (5) Fagus sylvatica. } \\
{ }^{1} \text { The full description of the indicators, meta-models and input data specifics can be found in Holman and Harrison (2012). } \\
{ }^{2} \text { European Soil Data Centre (ESDAC): http://eusoils.jrc.ec.europa.eu/data.html. } \\
{ }^{3} \text { CORINE Land Cover Data (CLC): https://land.copernicus.eu/pan-european/corine-land-cover. } \\
{ }^{4} \text { EUROSTAT Nomenclature of Territorial Units for Statistics (NUTS) data: http://lepp.eurostat.ec.europa. } \\
\text { eu/portal/page/portal/nuts_nomenclature/introduction. } \\
{ }^{5} \text { WaterGAP is a widely used global freshwater model and data specifics are described in detail elsewhere (e.g., Alcamo et al. (2003); } \\
\text { http://Www.watergap.de). }\end{array}$} \\
\hline
\end{tabular}

Fig. 1 illustrates the methodology concept and framework applied in this study for understanding the key nexus interactions and their potential implications for sustainability under a range of climate and socioeconomic drivers combined into different scenarios.

The study particularly focuses on stylised scenario combinations of eight key exogenous drivers, which include four climatic (temperature, summer precipitation, winter precipitation, and $\mathrm{CO}_{2}$ concentration) and four socio-economic (population, GDP, food imports, and agricultural yields) factors. They are identified based on an extensive local sensitivity analysis of the IAP, via a One-Driver-at-a-Time (ODAT) approach, focusing on those drivers that have 'strong' and 'non-linear' effects on more than one sector at the European scale (Kebede et al. 2015). A total of 915 scenario combinations are identified, which are sampled from a larger set of ( 1800 , referred hereafter as the 'full-range') scenario combinations of the above eight key drivers. The full-range scenarios were used to define the overall uncertainty space for a global, multi-dimensional sensitivity analysis of the IAP conducted using a Multiple-Drivers-at-a-Time (MDAT) approach (Kebede 2016). The combined ODAT and MDAT approaches are used as a basis for a systematic screening of the key drivers of change and plausibility of their scenario combinations used to explore the key uncertainties in cross-sectoral impacts and their spatial variability across Europe (see Fig. 1). The full-range IAP simulation runs consisted of 1200 climate scenarios and 600 socio-economic scenarios. They represent driver combinations considering a varying (4-8) number of states (values) for each driver as summarised in Table 2. 


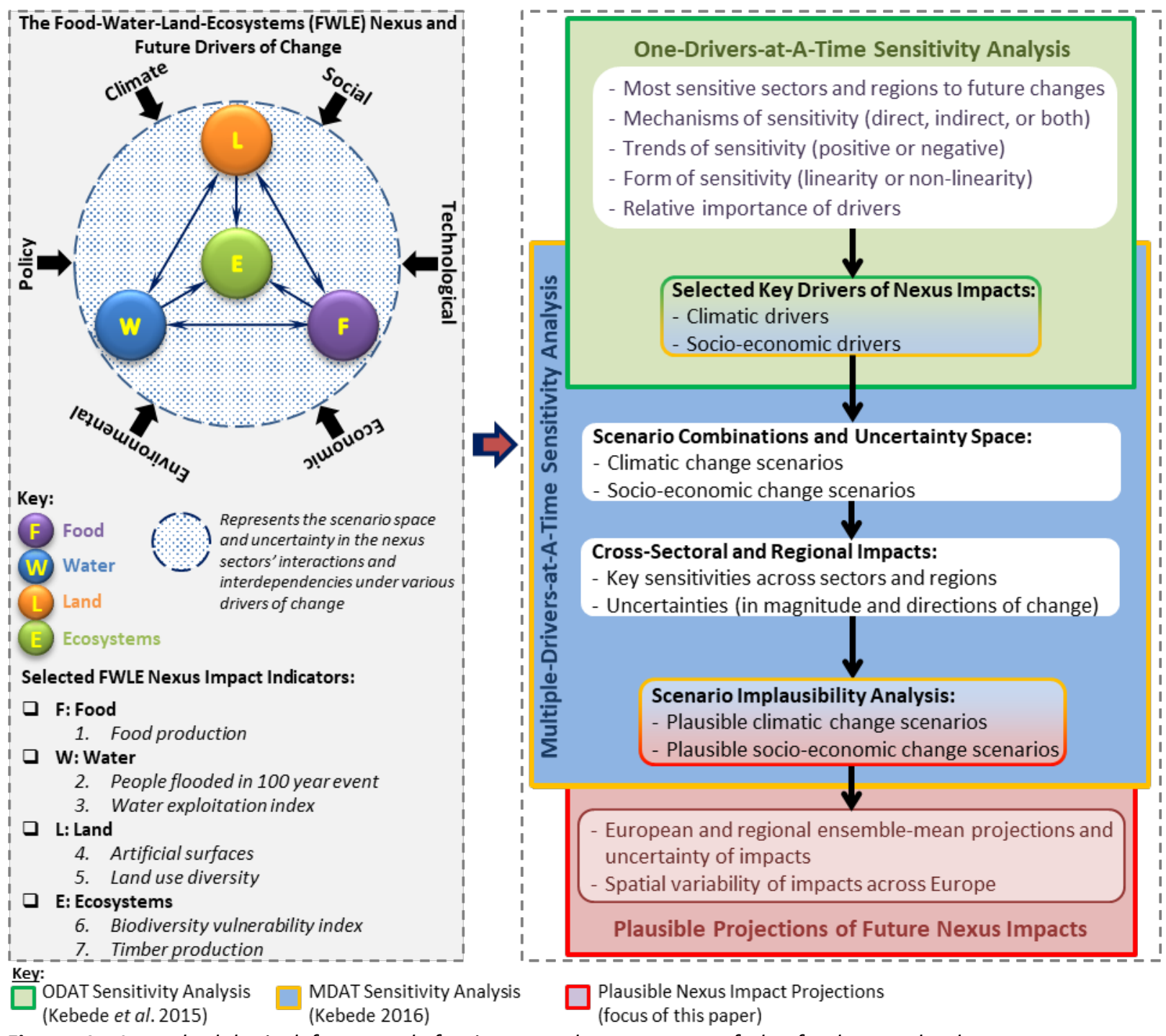

Figure 1: A methodological framework for integrated assessment of the food-water-land-ecosystems nexus in Europe using the CLIMSAVE IAP for sensitivity and scenario analysis.

Table 2: Selected values of the climate and socio-economic change drivers used in the full-range scenario simulations. Dubrovsky et al. (2015) and Kok et al. (2015) provide detailed descriptions of the selection process and data used in defining the value ranges for each climatic and socio-economic driver.

\begin{tabular}{|l|c|c|c|}
\hline Change Driver & Minimum & Maximum & Interval \\
\hline Climate Change & \multicolumn{3}{|l|}{} \\
\hline Temperature change ( $\left.{ }^{\circ} \mathrm{C}\right)$ & 0 & 5 & 2 \\
\hline Precipitation (Winter) (\%) & -50 & 50 & 25 \\
\hline Precipitation (Summer) (\%) & -50 & 50 & 50 \\
\hline $\mathrm{CO}_{2}$ concentration (ppm) & 350 & 700 & 25 \\
\hline Socio-Economic Change & -50 & 50 & 20 \\
\hline Population (\%) & -20 & 200 & $-20 \%$, then every 50\% from 0 \\
\hline Gross Domestic Product (GDP) (\%) & -40 & 40 & 50 \\
\hline Food Imports (\%) & -50 & 100 & \\
\hline Agricultural Yields (\%) &
\end{tabular}

The 'implausibility' analysis used in this paper for sampling a smaller set of credible scenarios from the full set is based on the approach developed and applied by Edwards et al. (2011). They used a sequential design experiment in order to assess the parameter-space of their model and identify 'low-dimensional regions that are implausible'. This is based on identifying key model pre-calibration outputs and 'physical' ranges by determining what is classed as 'non-physical' for their model. In this study, possible ranges of the selected impact indicators are identified based on a review of the literature on future projections of each indicator. The ranges are used to identify those MDAT scenarios that are considered as 'not- 
implausible' and used for further analysis. In the absence of consistent data to define the 'physical' ranges of the seven diverse cross-sectoral impact indicators considered, the approach captures diverse 'expert opinions' and associated assumptions and methods employed in the literature. It also allows the key nexus impacts to be assessed using a consistent scenario and modelling approach within a single integrated framework. In addition, it helps identify spatial and regional variations within the Europe-wide projection ranges explored. Fig. 2 summarises the literature-based ranges of projections and their percentile distributions for each nexus impact metric. The broad range of estimates summarised also highlights the high uncertainties in future projections of changing conditions and their impacts in Europe.
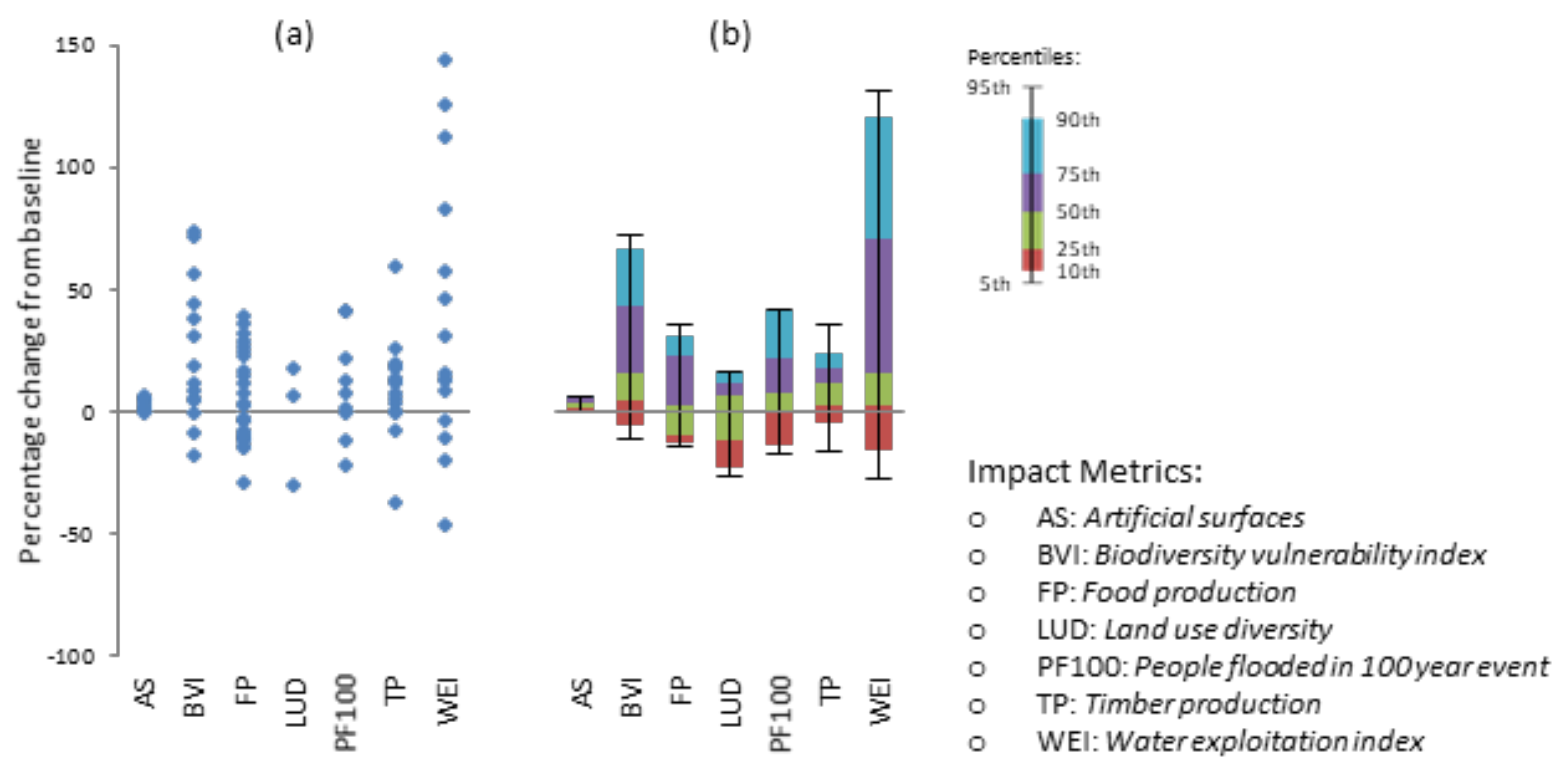

Figure 2: Summary of (a) the ranges and (b) percentile distributions of future projections of changes in the seven impact metrics (see ESM).

Considering the above ranges as boundary conditions, a total of 838 climate (70\%) and 77 socioeconomic ( $13 \%$ of the 'full range') scenarios are selected as plausible and applied in this study to estimate: (i) the ensemble-mean and uncertainty of the area-aggregated projections and (ii) the Europewide spatial distributions of nexus impacts across the scenarios. The first is modelled for Europe and its four sub-regions (eastern, northern, southern, and western Europe). The sub-regions are defined based on river basin classifications, chosen to have a consistent scale of analysis across all sectors (Kebede $\mathrm{et}$ al. 2015). The second is modelled based on a $10 \times 10$ arc-minutes grid resolution (i.e., $\sim 16 \mathrm{~km} \times 16 \mathrm{~km}$ at the equator), which results in a total of 23,871 grid cells across Europe (covering the EU27, plus Norway, Switzerland, and United Kingdom). The results provide plausible and consistent (across sectors, regions, and scenarios) projections of future climate and socio-economic change impacts across Europe.

3. Results and Discussion

\subsection{Baseline Estimates and Overview of Nexus Impacts across the Scenarios}

The FWLE nexus synergies and trade-offs are represented by key interactions between the seven impact metrics explored under the various climate and socio-economic scenarios (Fig. 3). 


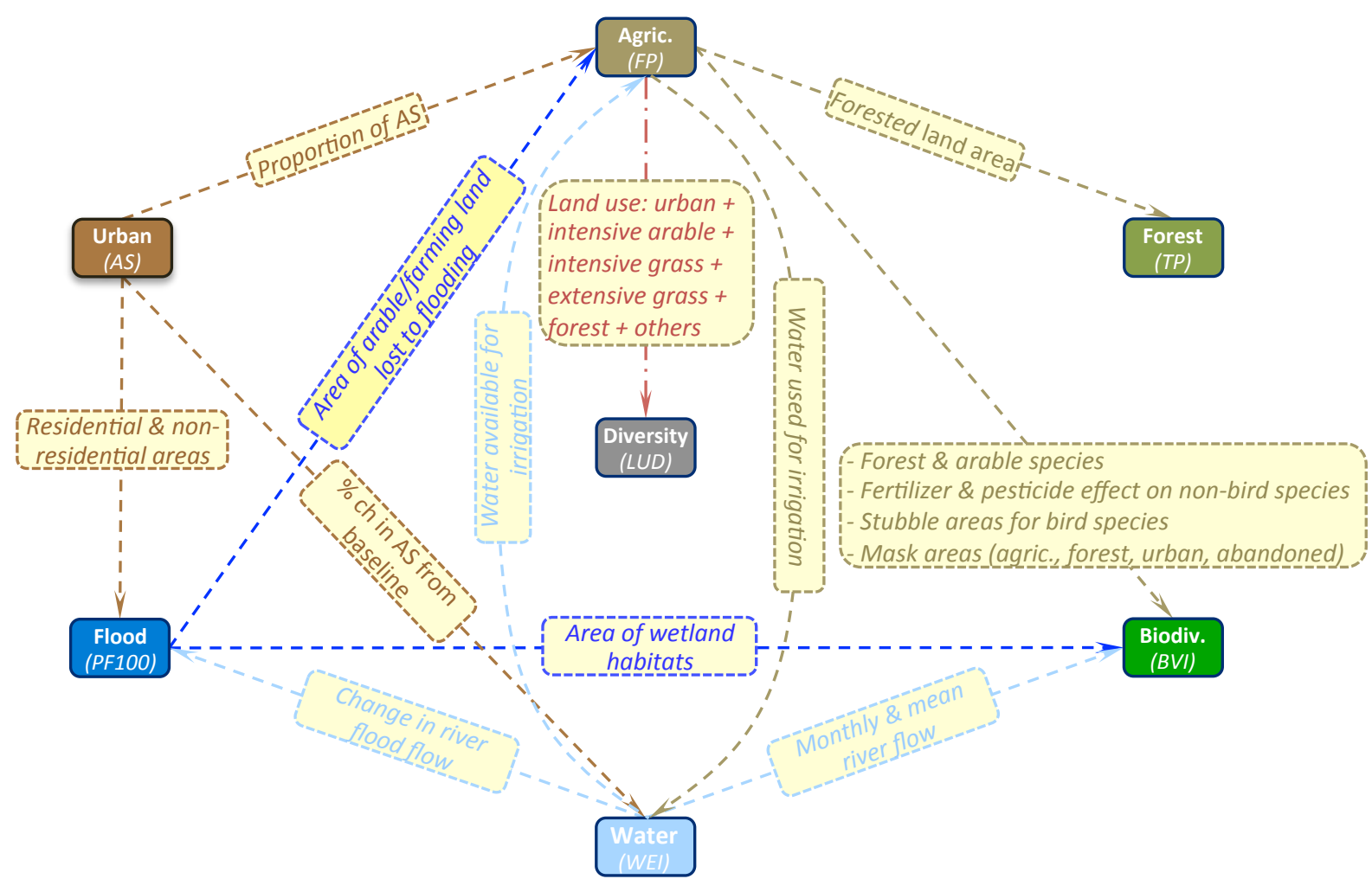

Figure 3: Simplified schematic diagram of the sectoral linkages and key interactions between the selected nexus impact metrics.

Table 3 summarises area-aggregated baseline estimates of the nexus impact metrics and study regions. The percentage change projections presented in the paper are relative to these estimates. The sources and year of baseline data used for each indicator are discussed in more detail in Holman \& Harrison (2012).

Table 3: Area-aggregated baseline values of the seven nexus impact metrics.

\begin{tabular}{|l|rrrrr|}
\hline \multirow{2}{*}{ Nexus Impact Metrics } & \multicolumn{4}{|c|}{ Study Areas/Regions ${ }^{+}$} \\
\cline { 2 - 6 } & WE & SE & EE & NE & EU \\
\hline AS: Artificial surfaces (\%) & 6.5 & 3.0 & 4.1 & 1.2 & 3.7 \\
BVI: Biodiversity vulnerability index (-) & 0.0 & 0.0 & 0.0 & 0.0 & 0.0 \\
FP: Food production (*1000 TJ) & 4754 & 2473 & 2021 & 597 & 9845 \\
LUD: Land use diversity (-) & 0.51 & 0.59 & 0.58 & 0.33 & 0.48 \\
PF100: People flooded in 100 year event (millions) & 8.3 & 3.4 & 4.7 & 1.1 & 17.5 \\
TP: Timber production (Gt) & 106.5 & 35.6 & 47.4 & 72.8 & 262.3 \\
WEI: Water exploitation index (-) & 0.19 & 0.27 & 0.18 & 0.02 & 0.15 \\
\hline${ }^{+}$WE: Western Europe, SE: Southern Europe, EE: Eastern Europe, NE: Northern Europe, and EU: Europe \\
\hline
\end{tabular}

Fig. 4 shows statistical distribution of the nexus impacts under the various climate and socio-economic scenarios. For most indicators, changes under the socio-economic scenarios are relatively smaller than that of the climate scenarios across the study areas. However, there are significant variations in the distribution across the sectors, regions, and scenarios. At the European scale, most indicators increase in more than $50 \%$ of the climate scenarios, except for food production (only $10 \%$ ), land use diversity (just $1 \%$ ), and artificial surfaces (no change). Both the water stress and biodiversity vulnerability indices show the highest increase (by more than $47 \%$ and $17 \%$, respectively) in at least a quarter of the climate scenarios.

In contrast, almost all indicators show a Europe-wide increase in at least $40 \%$ of the socio-economic scenarios. The two exceptions are land use diversity and timber production, which decline in almost all the scenarios. The water, agriculture, and flood impact indicators experience the highest increase $(61 \%$, $24 \%$, and $24 \%$, respectively) in a quarter of the socio-economic scenarios. 

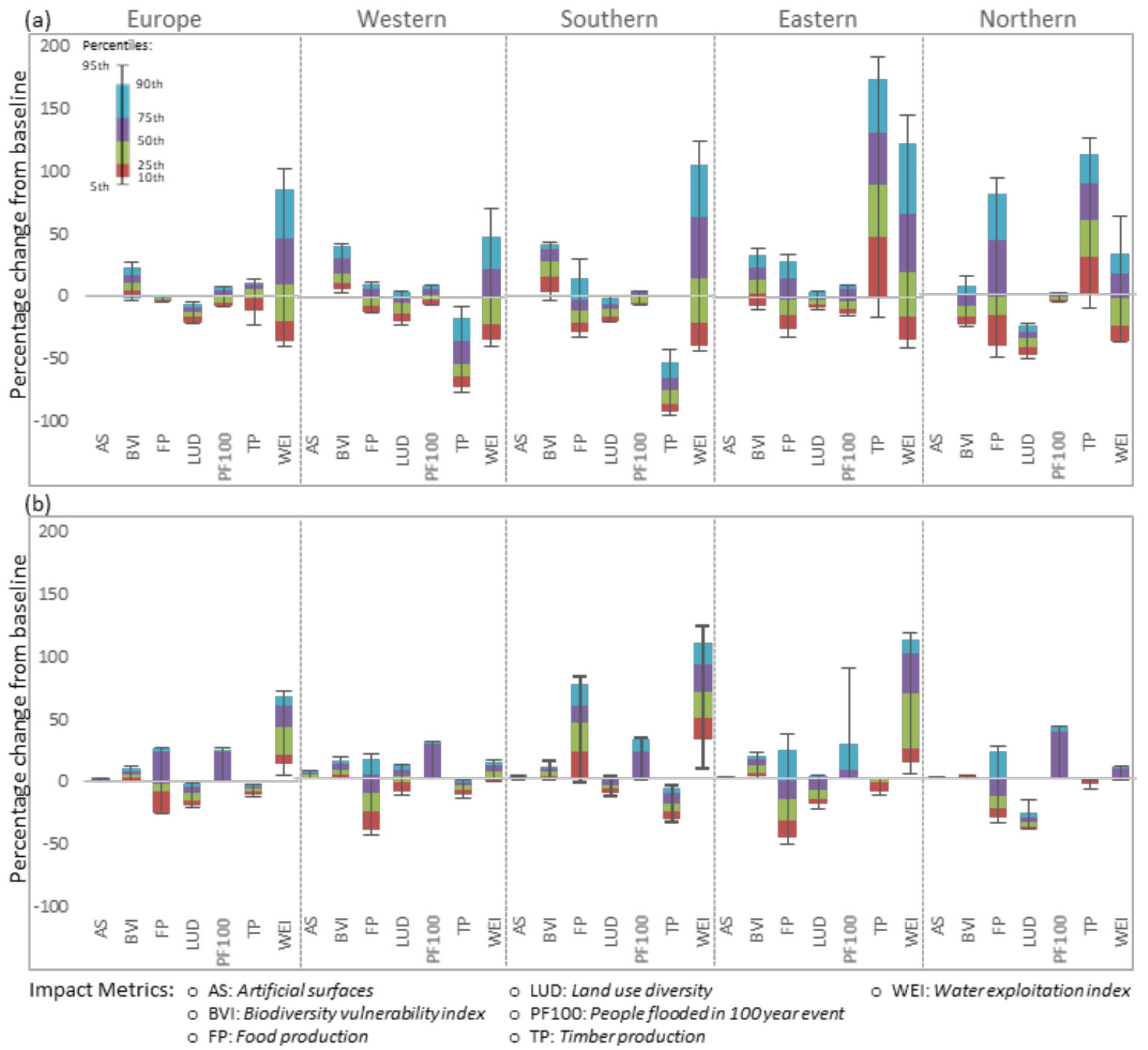

Figure 4: Percentile distribution of the \% change (from baseline) in the nexus impact metrics under the: (a) 838 climate scenarios and (b) 77 socio-economic scenarios investigated.

The regional change patterns due to climate change vary across the sectors. The biodiversity, water, flooding, and agriculture indicators increase in more than $41 \%$ of the scenarios on average across the four regions. Notable exceptions are biodiversity (northern) and agriculture (southern Europe), which decline in over $75 \%$ of the scenarios. There are regional variations for forestry and land use diversity. Timber production declines in western and southern Europe in nearly all (over 97\%) the climate scenarios, while more than $90 \%$ of the scenarios lead to an increase in eastern and northern Europe. Similarly, land use diversity increases in western and eastern Europe in $30 \%$ of the scenarios, while declining in southern and northern Europe in $94 \%$ the scenarios. The highest changes (across all scenarios and regions) are observed for timber production, over $+59 \%$ in eastern and northern Europe and $-54 \%$ in other regions in half of the climate scenarios.

Under the socio-economic scenarios, water, biodiversity and urban sectors increase across all four regions in more than $73 \%$ of the scenarios. Albeit small in proportion in other regions, food production in southern Europe also increases in more than $90 \%$ of the scenarios. In contrast, other sectors decline across all regions under most of the socio-economic scenarios. The highest increases are estimated for water stress (68\% in southern and eastern Europe) and agriculture ( $45 \%$ in southern Europe).

\subsection{Uncertainty of European and Regional Impacts}

\subsubsection{Due to Climate Change}


The analysis is based on four key climatic factors (temperature, summer and winter precipitation, and $\mathrm{CO}_{2}$ concentration) combined into more than 800 scenarios sampling a wide range of uncertainty. The Europe-wide projections show that there is high uncertainty in the direction of change in all indicators across the scenarios. The scenario-specific extreme estimates range between: -46 and $+140 \%$ (water), 35 and $+25 \%$ (forest), -13 and $+37 \%$ (biodiversity), -12 and $+19 \%$ (agriculture), -26 and $+4 \%$ (land use diversity), and -11 and $+8 \%$ (flooding). The highest ensemble-mean change is observed for Europe-wide water stress, which increases by $17 \%$ (Fig. 5 ). This is partly due to a decline in water availability and/or increase in irrigation need across the scenarios. This is followed by an overall decline in land use diversity $(-13 \%)$ and an increase in biodiversity vulnerability $(+11 \%)$. In contrast, forest, agriculture and flooding show the least $(<3 \%)$ ensemble-mean change across the scenarios.

When looking at the mean \pm SD simulations, there is high uncertainty in the direction of change for water, forest and flooding. Other indicators, in contrast, show robust change across the scenarios, with an increase in biodiversity vulnerability and a decline in land use diversity and food production. In terms of magnitude, water stress shows the highest uncertainty $(-27 \%$ to $+62 \%)$. The large increase is mainly attributed to the extreme scenarios with high temperature increases and large declines in precipitation, affecting both the supply and demand side (Kovats et al. 2014). There is moderate uncertainty for timber production $(-8 \%$ to $+13 \%)$ and biodiversity vulnerability $(2-20 \%)$. Other indicators show a relatively small uncertainty $(S D<6 \%)$; with food production having the least variation $(<2 \%)$. The latter is mainly due to the implicit adaptation within the IAP to meet Europe-level demand, with important spatial and regional implications as elaborated below.

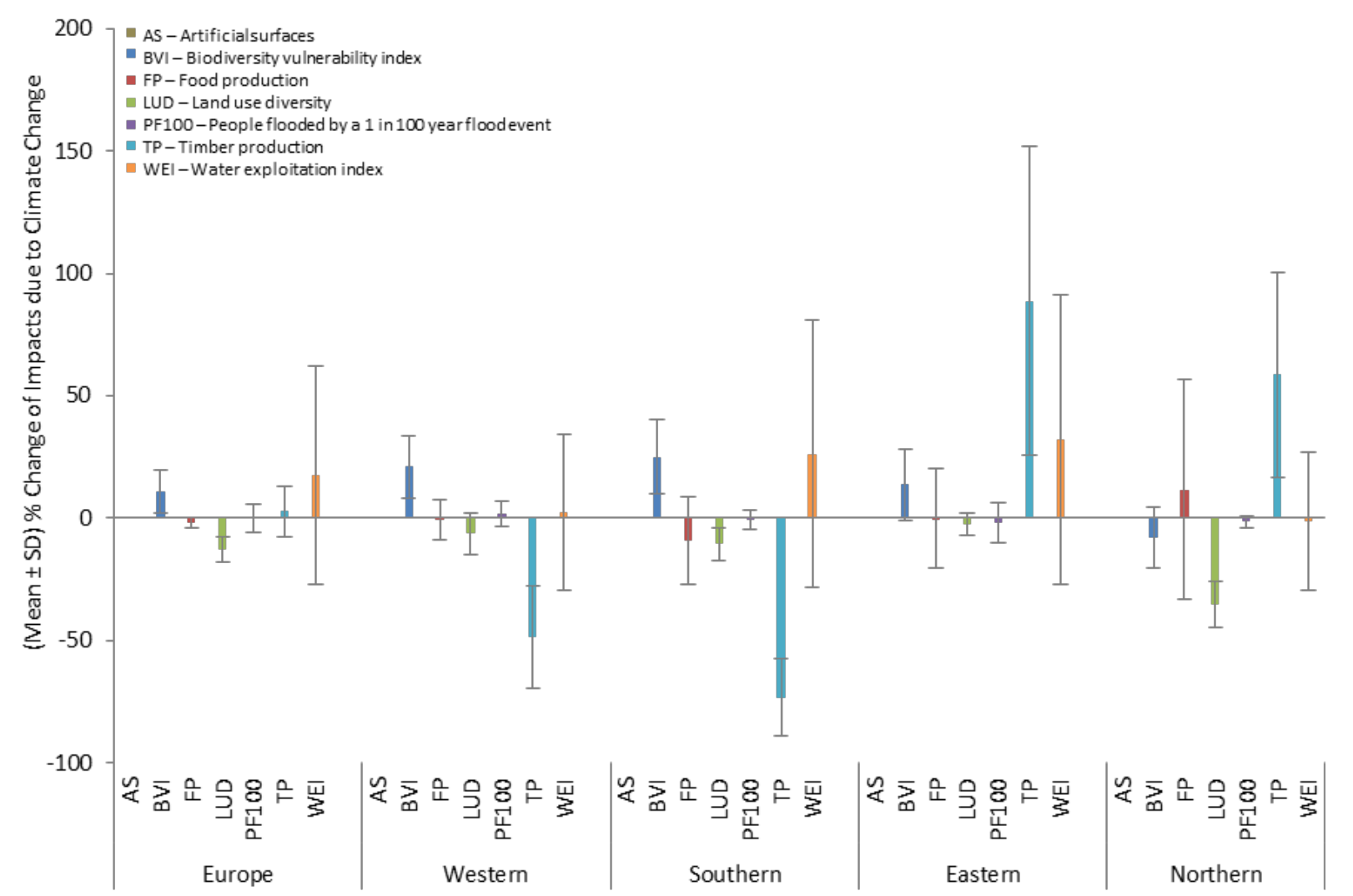

Figure 5: European and regional uncertainty of nexus impacts due to climate change based on (mean $\pm S D$ ) percentage change of the indicators from baseline. Coloured boxes represent the ensemble-mean across the scenarios, while error bars represent the SD from the mean.

There are notable regional variations both in terms of magnitude and direction of change. Under the ensemble-mean simulations, land use diversity declines across all four regions, by $\sim 35 \%$ in northern Europe. For other indicators, there are regional variations in the direction of change. In terms of magnitude, timber production and water stress show the highest changes, with varying levels and directions across the regions. Timber production declines by up to $73 \%$ in southern and western Europe; while increasing by more than $59 \%$ in eastern and northern Europe. Similarly, the largest increase in 
water stress is in southern (26\%) and eastern (32\%) Europe, while change is minimal in northern Europe. Biodiversity vulnerability is also projected to increase by $14 \%-25 \%$ across three regions, while northern Europe see some improvement (by $8 \%$ ). The ensemble-mean changes in flood impacts are relatively small $(<2 \%)$ across all four regions.

The ensemble-mean simulations also demonstrate that food production declines across three regions, by up to $9 \%$ in southern Europe. This is, however, compensated by a $12 \%$ increase in production in northern Europe, resulting in overall Europe-wide production being maintained at or close to baseline levels. This is driven by the autonomous adaptation within the land use allocation module in prioritising food production to meet Europe-wide demand (Audsley et al. 2015). The model determines the most optimal locations in Europe for crops and/or livestock when trying to meet food demand. This results in changing spatial patterns for agriculture for different scenarios with knock-on effects for forestry (competition for land), water (irrigation needs) and biodiversity (habitat availability) and changes in land use diversity. Veerkamp et al. (2020) also demonstrated similar Europe-wide observations even under the most optimistic scenarios. On the other hand, the declines in both land use diversity and biodiversity vulnerability in northern Europe reflect the northward shift of agriculture under extreme climate scenarios, dominating the land use (hence reducing diversity) and increasing habitat space (especially for arable-related species, hence reducing vulnerability).

Focusing on the mean \pm SD estimates, there are robust directions of change in some of the indicatorregion combinations across the climate scenarios. These include: a decline in timber production (western and southern) and land use diversity (southern and northern Europe) and increasing timber production (eastern and northern) and biodiversity vulnerability (western and southern Europe). There is, however, uncertainty in the direction of change in the remaining indicator-region combinations (Fig. 5). In terms of magnitude, timber production shows the largest uncertainty: increasing by $25-152 \%$ (eastern) and $17-$ $101 \%$ (northern) and declining in western (25-70\%) and southern Europe (58-89\%). Water stress follows with changes ranging between $-29 \%$ and $+92 \%$ across all four regions. For agriculture, the largest uncertainty is observed in northern Europe (i.e., $-33 \%$ to $+57 \%$ ), followed by eastern and southern Europe $(-27 \%$ to $+20 \%)$. In contrast, biodiversity vulnerability shows relatively moderate uncertainty, with a standard deviation of just $14 \%$ averaged across the four regions. The larger uncertainty is estimated between $+10 \%$ and $+40 \%$ (southern) and $-1 \%$ and $28 \%$ (eastern Europe). Land use diversity and flooding generally show the least variation around the ensemble-mean, with $S D<7 \%$ across the regions and scenarios.

\subsubsection{Due to Socio-Economic Change}

The analysis explored more than 75 scenario combinations of four key socio-economic factors (i.e., population, GDP, food imports, and agricultural yields). The Europe-wide scenario-specific extreme projections range between: $-1 \%$ and $+79 \%$ (water), $-26 \%$ and $+29 \%$ (agriculture), $-25 \%$ and $-1 \%$ (land use diversity), $-17 \%$ and $0 \%$ (forestry), +1 and $+14 \%$ (biodiversity), +24 and $+27 \%$ (flooding), and 0 and $+3 \%$ (urban). This illustrates that there is more robustness in the extreme changes in most sectors under the socio-economic scenarios than the climate scenarios (see Section 3.2.1). For the ensemble-mean simulations, water stress shows the largest increase (42\%, Fig. 6). Similarly, the number of people flooded and biodiversity vulnerability increase by $10 \%$ and $6 \%$, respectively. In contrast, land use diversity and timber production are projected to decline by $10 \%$ and $6 \%$, respectively. Food production shows the least change (just $+1 \%$ ), again due to the autonomous adaptation considered in the IAP.

When considering the mean $\pm S D$ simulations, there is robustness in the direction of change for most sectors, except agriculture and flooding. The water, biodiversity and urban sectors show an increase, while land use diversity and forestry decline. In terms of magnitude, water stress $(20-63 \%)$ and food production $(-26 \%$ and $+29 \%)$ show the largest uncertainty across the scenarios. This is followed by people flooded $(-3 \%$ and $+22 \%)$ and land use diversity $(-16 \%$ and $-4 \%)$. Biodiversity, forest, and urban indicators show the least variation around the mean (with $\mathrm{SD}<5 \%$ ), ranging between $2-9 \%,-9$ to $-3 \%$, and $0-3 \%$, respectively. 


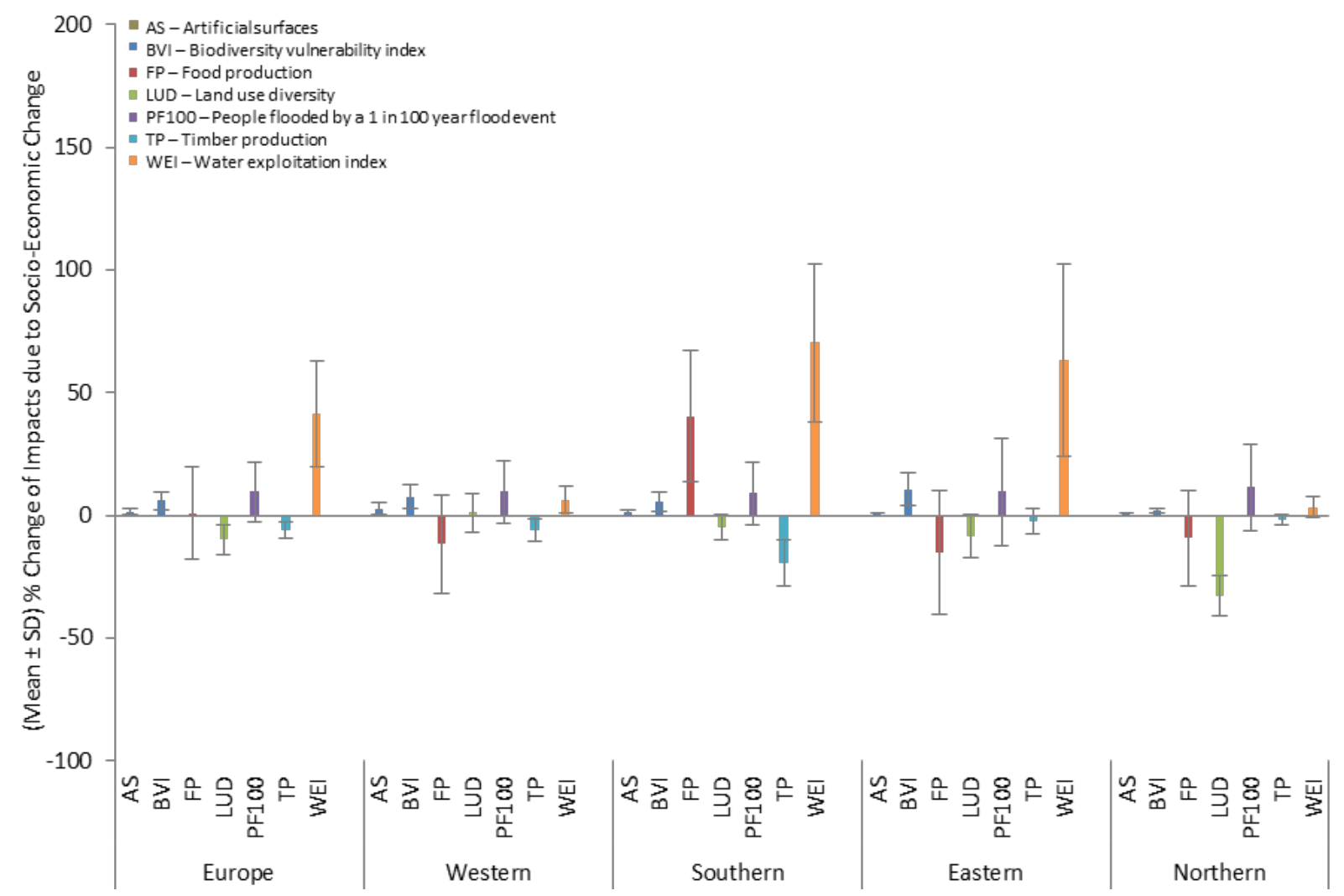

Figure 6: European and regional uncertainty of nexus impacts due to socio-economic change based on (mean $\pm S D$ ) percentage change of the indicators from baseline. Coloured boxes represent the ensemble-mean across the scenarios, while error bars represent the SD from the mean.

As in the climate scenarios, there are important regional variations (both in direction and magnitude of changes) under the socio-economic scenarios (Fig. 6). For the ensemble-mean simulations, most indicators are projected to get worse across all four regions, with only a few exceptions. In terms of magnitude, water stress is projected to increase by more than $63 \%$ in southern and eastern Europe, while there is a relatively small $(<6 \%)$ change in western and northern Europe. Food production follows with a $40 \%$ increase in southern Europe. However, it is expected to decline by up to $15 \%$ across the other three regions. Except in western Europe (where it is expected to improve by just 1\%), land use diversity is also projected to decline by up to $33 \%$ in northern Europe. Similarly, timber production is projected to decline across all four regions, with the largest in northern Europe $(19 \%)$ and by $2-6 \%$ in other regions. Although relatively smaller in magnitude, there is also a consistent increase in the number of people flooded $(9-12 \%)$ and biodiversity vulnerability $(2-11 \%)$ across all regions. Artificial surfaces show the least change, with $<3 \%$ increase across all four regions.

When comparing uncertainties based on the mean $\pm S D$ simulations, there is robustness in the direction of change in most indicator-region combinations (with varying degrees of magnitude). Similar to the climate scenarios, timber production (western and southern) and land use diversity (northern Europe) are projected to decline across the socio-economic scenarios. In contrast, water stress (in all except northern Europe), food production (southern), biodiversity vulnerability and urbanisation (all regions) are all projected to increase. However, there is uncertainty in the direction of change in other indicatorregion combinations, including flooding in all regions. In terms of magnitude, again water stress shows the largest change in eastern and southern Europe (24-103\%, Fig. 6). In other regions, the ranges are relatively small (with $\mathrm{SD}<5 \%$ ). In contrast, food production is projected to increase by $14-67 \%$ in southern Europe, while in other regions it is projected to both increase and decrease (between $-40 \%$ and $+10 \%$ ) across the scenarios. The number of people flooded is also projected between $-12 \%$ and $32 \%$ (the largest change in eastern Europe). Other indicators show relatively small to moderate variation, with $\mathrm{SD}<10 \%$ across all regions and scenarios. In comparison, timber production and land use diversity show a relatively larger uncertainty range, particularly in southern (timber by up to $-29 \%$ ) and eastern (diversity by up to $-17 \%$ ) Europe. Other indicator-region combinations with comparable variations also include land 
use diversity in northern (-41 to $-25 \%)$ and western (-7 to 9\%) and biodiversity vulnerability in eastern (4$17 \%)$ Europe. Urban change shows the least variation ( $S D<3 \%)$ across all regions and scenarios.

\subsubsection{Comparison of Impacts due to Climate and Socio-Economic Change}

Table 4 summarises a comparison of implications of the climate and socio-economic scenarios to highlight the degree and main sources of uncertainty for each nexus indicator. This is based on ranking of the standard deviation (relative to the ensemble-mean) and sensitivity range (difference between the extreme minimum and maximum projections) across the scenarios.

Table 4: Comparing the standard deviation (left) and sensitivity range (right) of the Europe-wide and regional percentage changes of the indicators across the scenarios. The red and blue texts and shading represent the climate (CD) and socio-economic (SED) scenarios, respectively. Table 3 defines the code names used here for the indicators and regions.

\begin{tabular}{|c|c|c|c|c|c|c|}
\hline \multirow{2}{*}{\multicolumn{2}{|c|}{$\begin{array}{c}\text { Highest Standard } \\
\text { Deviation }\end{array}$}} & \multicolumn{5}{|c|}{ Regions } \\
\hline & & EU & WE & SE & $\mathrm{EE}$ & $\mathrm{NE}$ \\
\hline \multirow{7}{*}{ 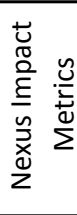 } & AS & 1.2 & 2.5 & 1.1 & 0.4 & 0.6 \\
\hline & BVI & 8.9 & 12.6 & 15.1 & 14.6 & 12.3 \\
\hline & FP & 19.0 & 20.0 & 26.8 & 25.3 & 44.9 \\
\hline & LUD & 6.2 & 8.5 & 6.5 & 8.8 & 9.5 \\
\hline & PF100 & 12.0 & 13.0 & 12.8 & 22.0 & 17.7 \\
\hline & TP & 10.6 & 21.1 & 15.9 & 63.4 & 42.1 \\
\hline & WEI & 44.6 & 31.8 & 54.7 & 59.3 & 28.0 \\
\hline
\end{tabular}

\begin{tabular}{|c|c|c|c|c|c|c|}
\hline \multirow{2}{*}{\multicolumn{2}{|c|}{$\begin{array}{c}\text { Highest Sensitivity } \\
\text { Range }\end{array}$}} & \multicolumn{5}{|c|}{ Regions } \\
\hline & & $\mathrm{EU}$ & WE & SE & $\mathrm{EE}$ & $\mathrm{NE}$ \\
\hline \multirow{7}{*}{ 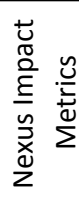 } & $\overline{A S}$ & 3 & 7 & 3 & 1 & 1 \\
\hline & BVI & 50 & 57 & 79 & 78 & 70 \\
\hline & FP & 55 & 70 & 112 & 100 & 256 \\
\hline & LUD & 30 & 38 & 36 & 31 & 67 \\
\hline & PF100 & 20 & 23 & 30 & 81 & 27 \\
\hline & TP & 59 & 112 & 97 & 332 & 258 \\
\hline & WEI & 187 & 135 & 246 & 291 & 115 \\
\hline
\end{tabular}

At the European scale, socio-economic factors dominate the largest sensitivity in food production and urbanisation, while other sectors' sensitivity is driven by climatic factors. Regionally, in almost all cases, either climate or socio-economic factors dominate the potential uncertainty of individual nexus impacts across all regions, with a few exceptions (see Table 4). Exceptions include food production in northern and southern Europe (depending on which metric considered) and land use diversity in eastern Europe. The largest uncertainty in most impact indicators is mainly due to the uncertainty in climate change. This is particularly true for timber production in eastern and northern Europe and water stress across most regions. While socio-economic factors play an important role in other regions, climate change is projected to drive the potential shift in agriculture towards northern Europe as warmer climate makes the region more productive. Climate change will also have important implications for biodiversity across all regions. In contrast, uncertainty in changes in regional flood impacts and urbanisation is mainly driven by socio-economic factors. These results highlight the importance of understanding the full uncertainties due to both climate and socio-economic change impacts across the nexus sectors. The following two sections discuss the grid-based spatial variation of these changes in more detail.

\subsection{Spatial Distribution of Nexus Impacts across Europe}

The area-aggregated results presented by region in previous sections average out sub-regional spatial variations of future changes in nexus impacts. This section presents the spatial distribution of each indicator based on the grid-based ensemble-mean simulations across the various climate and socioeconomic scenarios.

\subsubsection{Climate Change Scenarios}

Fig. 7 displays spatial distribution of the potential hotspots of significant ensemble-mean changes ( $>50 \%$ from baseline) in nexus impacts across the climate scenarios. Biodiversity vulnerability and water stress show moderate $(>5 \%)$ increase in almost $60 \%$ of the grids across Europe, resulting in a Europe-wide average increase of about $11 \%$ and $17 \%$, respectively. Water stress hotspot areas due to climate change are identified in parts of Spain and Portugal, southern Italy, Romania, Bulgaria and Poland, covering $\sim 13 \%$ of European grids. Similarly, southern France and Italy, some alpine areas in continental Europe and Denmark are potential hotspots for biodiversity vulnerability. This is partly due to the decline in arable habitats and climate suitability for some species under some of the scenarios. In contrast, parts of northern Europe (particularly southern Finland and alpine areas in Scandinavia), western Romania and Ireland are projected with a significant improvement in biodiversity. This is mainly associated with a northward shift in habitat distribution under warmer climate scenarios. The biodiversity module assumes that species will be able to disperse to occupy new climate and habitat space, so it may overestimate 
biodiversity suitability in the north. Similarly, while the Europe-wide number of people affected by coastal and fluvial floods is relatively unchanged, there are important local implications. These areas represent about $6 \%$ of European girds, with hotspot areas particularly concentrated in western Europe (e.g., northern Germany), mainly due to a significant increase in precipitation.

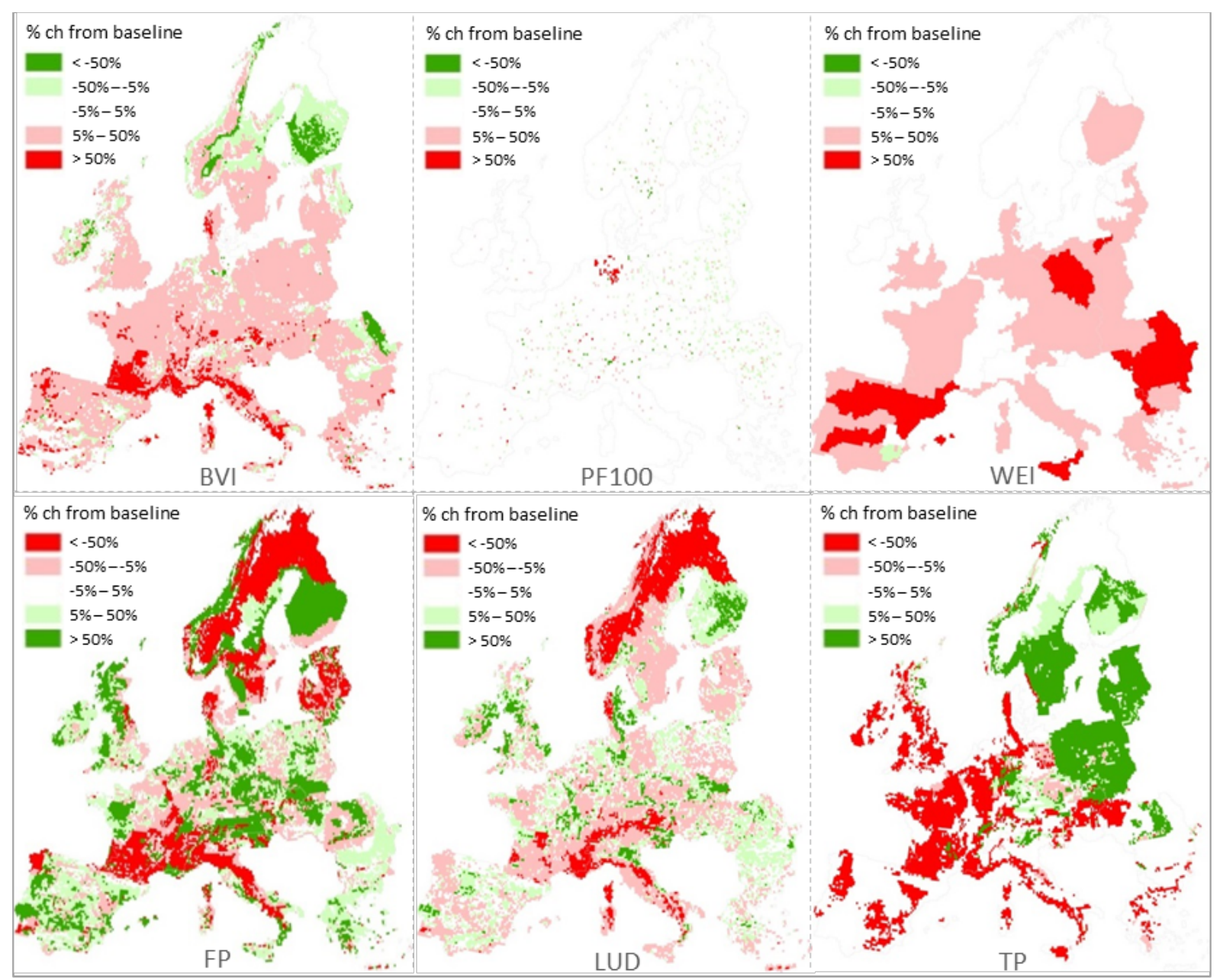

Figure 7: Spatial distribution of the percentage change (from baseline) of nexus impacts in Europe based on gridlevel ensemble-mean simulations across the climate scenarios.

Land use diversity shows moderate decline in $53 \%$ of the girds across Europe, resulting in a Europe-wide average decline by $13 \%$. Areas with the largest decline $(>50 \%)$ in land use diversity are concentrated in northern Europe (representing $\sim 12 \%$ of Europe's grids). Similar hotspot areas are also found in the Mediterranean (e.g., southeast France and northwest Italy, covering 3\% European grids). Such declines in diversity are often driven by changes in agricultural land use, which has cascading adverse implications on other sectors. For food production, while the Europe-wide average decline is $<2 \%$, there are significant variations spatially. A moderate decline in food production is observed in $45 \%$ of the grids, while increasing by the same proportion in a similar number of grids elsewhere across Europe. Areas with the largest $(>50 \%)$ decline in food production are mainly in parts of southern and northern Europe (covering 17\% European grids). In contrast, expansion of intensive agriculture in some areas leads to an increase in production by $>50 \%$ in a quarter of the grids across Europe. Larger proportions of this are distributed across northern ( $9 \%$ of grids) and western ( $8 \%$ ) Europe, while the rest in southern and eastern Europe ( $3 \%$ of grids in each region). These areas are considered as key agricultural land for maintaining Europe-wide baseline level production under the various climate scenarios. However, this has important implications on other sectors including timber production, which declines significantly (by $>50 \%$ ) across most parts of western and southern Europe. This is mainly associated with conversion of forest areas to intensive agriculture to meet Europe-wide food provision priorities. In contrast, a combination of greater yield potential in some areas and overall profitability in other areas lead to an 
overall increase in timber production in northern and eastern Europe (particularly in the north) under some of the climate scenarios.

\subsubsection{Socio-Economic Change Scenarios}

Fig. 8 shows the spatial distribution of potential hotspots of nexus impacts based on grid-based ensemble-mean simulations under the socio-economic scenarios. Unlike the climate scenarios, there are consistent adverse changes in most indicators, albeit with varying magnitudes, across large areas of Europe. The water index shows moderate increase in half of the grids in Europe, leading to a Europewide average increase by $41 \%$. However, large areas of southern and eastern Europe (covering $17 \%$ of European grids) are identified as water stress hotspots. Similarly, there is wide spread increase in biodiversity vulnerability and number of people flooded across Europe. This represents a moderate increase in $30 \%$ and $20 \%$ of the grids, respectively, which lead to a Europe-wide average increase of $6 \%$ (biodiversity) and $10 \%$ (flooding). Areas such as southern parts of Spain and Portugal, alpine areas in Austria, southeast France, northern Germany and various areas in Italy are identified as hotspots in biodiversity vulnerability, although collectively they represent only a small proportion (just $1 \%$ ) of grids across Europe. Similarly, flood impact increases by $>25 \%$ in $3 \%$ of grids spread across Europe. Unlike the climate scenarios, there are no or very few grids that experience a reduction in impacts on biodiversity and water. This is mainly driven by the increase in population in some of the socio-economic scenarios, which affects the number of people living within flood plains (hence flood impacts), demand for water (e.g., for irrigation or domestic use, affecting water stress), and land use change (with implications on species distribution).

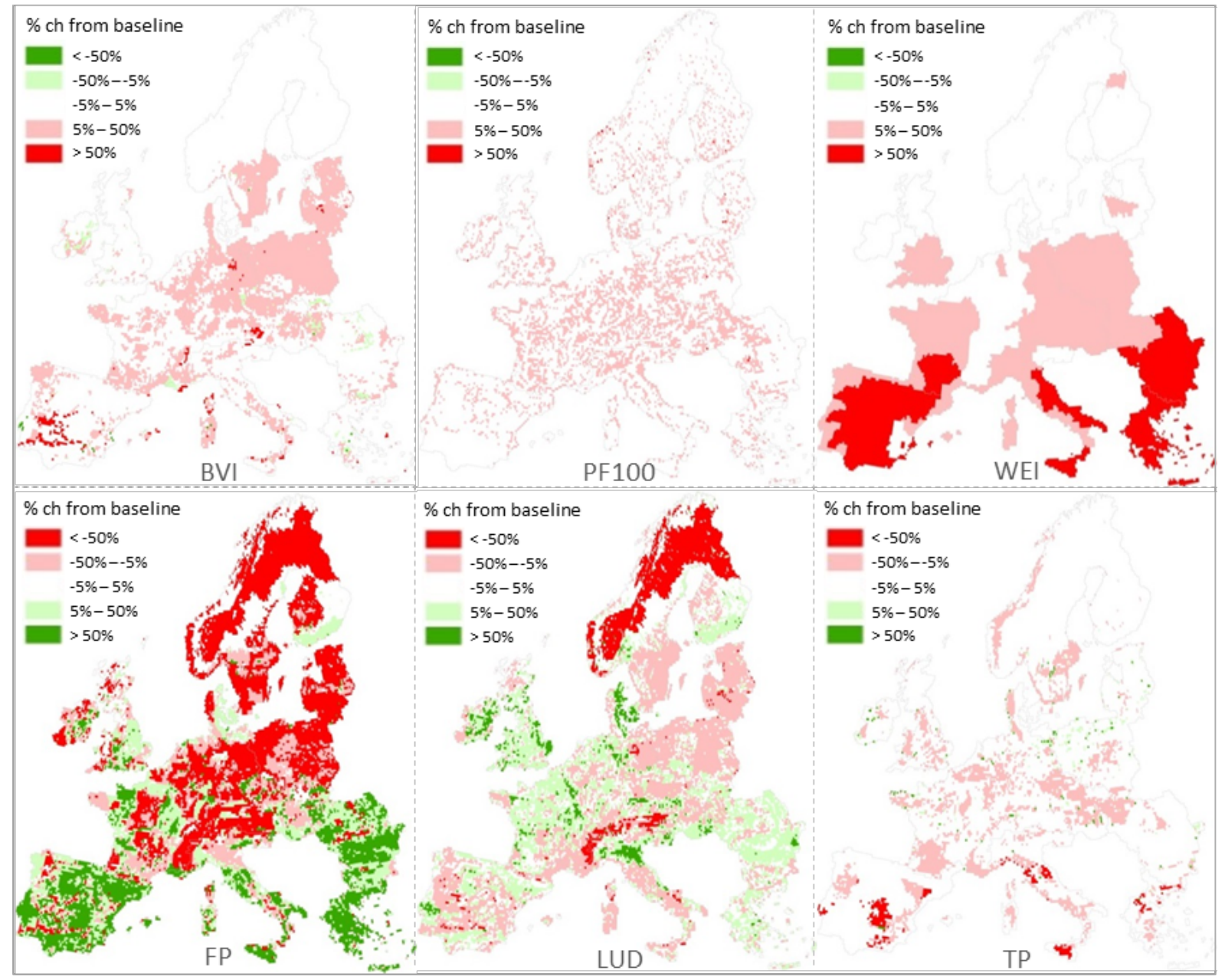

Figure 8: Spatial distribution of the percentage change (from baseline) of nexus impacts in Europe based on gridlevel ensemble-mean simulations across the socio-economic scenarios.

While the Europe-wide ensemble-mean food production is projected to increase by just $1 \%$, there is a clear regional divide in the grid-based simulations in terms of the direction of change under the socio- 
economic scenarios. It shows moderate increase in $30 \%$ of the grids, while declining by the same proportion in $54 \%$ of Europe's grids. However, there are significant changes $(>50 \%)$ in food production, declining in $38 \%$ and increasing in $13 \%$ of the grids across Europe. The largest reductions mainly occur in northern ( $18 \%$ of grids) and western (11\% of grids across Europe) regions. In contrast, the largest increases in production occur in southern Europe ( $8 \%$ grids), followed by $5 \%$ of grids spread across western and eastern Europe. This is mainly a manifestation of the scenarios explored. On the one hand, scenarios with increases in food imports and agricultural yields lead to a reduction in production in less productive areas. On the other hand, scenarios that increase demand through higher population or decreases in food imports result in expansion of intensive agriculture in more productive areas. However, this has implications on other land use indicators such as diversity and forestry, which decline by $>5 \%$ in $45 \%$ and $18 \%$, respectively, of the grids across Europe. Land use diversity is also projected to increase by the same amount in $27 \%$ of the grids across Europe.

\section{Conclusions and Outlook}

The study demonstrated that there are important synergies and trade-offs across the FWLE nexus sectors and regions, and associated major land use constraints in Europe. In particular, there is a significant trade-off between food production and other components of the FWLE nexus, which needs to be recognised and analysed within cross-sectoral adaptation policy formulation (e.g., Karabulut et al. 2018; Maes et al. 2012; Mouysset 2017; Serrao-Neumann et al. 2014). The methodology presented also highlighted the potential benefits of systems integration and nexus approaches considering a multisector, multi-scale and multi-scenario perspective and quantitative insights to identify key nexus interactions. This is crucial for fostering synergies and co-benefits and managing damaging trade-offs and conflicts between sectors and regions in order to support sustainable and efficient use and integrated management of natural resources in Europe and beyond that are consistent with the SDGs.

While there is extensive qualitative and now a growing number of quantitative nexus frameworks and modelling exercises, important methodological and policy challenges still remain. In particular, comprehensive and quantitative cross-sectoral integration remains a challenge in terms of application and implementation of nexus approaches and their policy relevance to fully understand and address the highly interconnected sustainability challenges such as in achieving the SDGs (e.g., Liu et al. 2018). A holistic view of the complex nexus interactions and associated implications of multi-dimensional future changes (e.g., climate, social, technological, economic, environmental, and policy governance conditions) require major advances in development of integrated quantitative modelling approaches and tools. Key future research directions include broadening current nexus frameworks by incorporating more aspects of the socio-ecological system (e.g., health, energy sectors), considering dynamic feedback between sectors, incorporating wider range of important drivers (endogenous, exogenous), improving issues of scale (spatial, temporal), considering consistent representation of sectoral processes and similar level of model complexity between various sectors, and translating exploratory approaches to decision support tools. Vanham et al. (2019) demonstrated that an environmental footprint family analysis can provide key information to assess the water-energy-food-ecosystem (WEFE) nexus and measure progress towards the SDGs. Advances in complex data handling approaches such as emerging data science (also termed synonymously as 'big data') technologies can play an important role in this regard (e.g., Blair et al. 2019).

\section{Acknowledgements}

The research that led to this work has received funding from the European Commission Seventh Framework Programme under Grant Agreement No. 244031 (The CLIMSAVE project: Climate change integrated assessment methodology for cross-sectoral adaptation and vulnerability in Europe; www.climsave.eu). We are also grateful to all the scientists/modellers involved in the development of the IAP (listed here alphabetically: Eric Audsley, George Cojocaru, Robert Dunford, lan Holman, Mustafa Mokrech, Sophie Rickebusch, Mark Rounsevell, Santi Sabaté, Florian Sallaba, Anabel Sanchez, Mirek Trnka, and Florian Wimmer).

\section{References}

Albrecht TR, Crootof A, Scott CA et al. (2018) The water-energy-food nexus: A systematic review of methods for nexus assessment. Environmental Research Letters, 13, 043002. 
Alcamo J, Döll P, Henrichs T et al. (2003) Development and testing of the WaterGAP2 global model of water use and availability. Hydrological Sciences Journal, 48:317-337.

Allen C, Metternicht G, Wiedmann T (2018) Initial progress in implementing the Sustainable Development Goals (SDGs): a review of evidence from countries. Sustainability Science, 13:1453-1467.

Audsley E, Trnka M, Sabaté S et al. (2015) Interactively modelling land profitability to estimate European agriculture and forest land use under future scenarios of climate, socio-economics, and adaptation. Climatic Change, 128:251-227.

Bazilian M, Rogner H, Howells M et al. (2011) Considering the energy, water and food nexus: Towards an integrated modelling approach. Energy Policy, 39:7896-7906.

Blair GS, Henrys P, Leeson A et al. (2019) Data science of the natural environment: A research roadmap. Frontiers in Environmental Science, 7, 121.

Bleischwitz R, Spataru C, VanDeveer SD et al. (2018) Resource nexus perspectives towards the United Nations Sustainable Development Goals. Nature Sustainability, 1:737-743.

Dubrovsky M, Trnka M, Holman IP et al (2015) Developing a reduced-form ensemble of climate change scenarios for Europe and its application to selected impact indicators. Climatic Change, 128:169-186.

Dunford R, Smith AC, Harrison PA et al (2015) Ecosystem service provision in a changing Europe: adapting to the impacts of combined climate and socio-economic change. Landscape Ecology, 30:443-461.

Edwards NR, Cameron D, Rougier J (2011) Pre-calibrating an intermediate complexity climate model. Climate Dynamics, 37:1469-1482.

FAO (2011) The state of the world's land and water resources for food and agriculture (SOLAW) - Managing systems at risk. Food and Agriculture Organisation of the United Nations, Rome and Earthscan, London.

Feyen L, Dankers R, Bódis K et al (2012) Fluvial flood risk in Europe in present and future climates. Climatic Change, 112:47-62.

Geiger F, Bengtsson J, Berendse F et al. (2010) Persistent negative effects of pesticides on biodiversity and biological control potential on European farmland. Basic and Applied Ecology, 11:97-105.

Giddings B, Hopwood B, O’Brien G (2002) Environment, economy and society: Fitting them together into sustainable development. Sustainable Development, 10:187-196.

Harrison PA, Berry PM, Butt N et al. (2006) Modelling climate change impacts on species' distributions at the European scale: implications for conservation policy. Environmental Science and Policy, 9:116-128.

Harrison PA, Dunford R, Holman IP, Rounsevell DA (2016) Climate change impact modelling needs to include crosssectoral interactions. Nature Climate Change, 6:885-890.

Harrison PA, Dunford R, Savin C et al. (2015b) Cross-sectoral impacts of climate change and socio-economic change for multiple, European land- and water-based sectors. Climatic Change, 128:279-292.

Harrison PA, Holman IP, Berry PM (2015a) Assessing cross-sectoral climate change impacts, adaptation and vulnerability: An Introduction to the CLIMSAVE project. Climatic Change, 128:153-167.

Harrison PA, Holman IP, Cojocaru G et al. (2013) Combining qualitative and quantitative understanding for exploring cross-sectoral climate change impacts, adaptation and vulnerability in Europe. Regional Environmental Change, 13:761-780.

Henle K, Alard D, Clitherow J et al. (2008) Identifying and managing the conflicts between agriculture and biodiversity conservation in Europe - A review. Agricultural, Ecosystems \& Environment, 124(1-2):60-71.

Hoff H (2011) Understanding the Nexus. Background paper for the Bonn2011 Conference: The Water, Energy and Food Security Nexus. Stockholm Energy Institute, Stockholm, 51pp.

Holman IP, Brown C, Janes V et al. (2017) Can we be certain about future land use change in Europe? A multiscenario, integrated-assessment analysis. Agricultural Systems, 151:126-135.

Holman IP, Harrison PA (2012) Report describing the development and validation of the sectoral meta-models for $\begin{array}{lllll}\text { integration in } & \text { CLIMSAVE } & \text { Deliverable } & \text { D2.2 }\end{array}$ http://www.climsave.eu/climsave/doc/Report_on_the_Meta-models_updated.pdf Accessed 16 July 2019. 
Howells M, Rogner H-H (2014) Water-energy nexus: Assessing integrated systems. Nature Climate Change, 4:246247.

Hutton CW, Nicholls RJ, Lazar AN et al. (2018) Potential trade-offs between the Sustainable Development Goals in coastal Bangladesh. Sustainability, 10, 1108.

Jacob D, Kotova L, Teichmann C et al. (2018) Climate impacts in Europe under $+1.50 \mathrm{C}$ global warming. Earth's Future, 6:264-285.

Jäger J, Rounsevell MDA, Harrison PA et al. (2015) Assessing policy robustness of climate change adaptation measures across sectors and scenarios. Climatic Change, 128:395-407.

Karabulut AA, Crenna E, Sala S et al. (2018) A proposal for integration of the ecosystem-water-food-land-energy (EWFLE) nexus concept into life cycle assessment: A synthesis matrix system for food security. Journal of Cleaner Production, 172:3874-3889.

Kebede (2016) The food-water-land-ecosystems nexus in Europe: An integrated assessment. University of Southampton, Faculty of Engineering and the Environment, PhD Thesis, 387pp.

Kebede AS, Dunford R, Mokrech M et al. (2015) Direct and indirect impacts of climate and socio-economic change in Europe: a sensitivity analysis for key land- and water-based sectors. Climatic Change, 128:261-277.

Kluts I, Wicke B, Leemans R et al. (2017) Sustainable constraints in determining European bioenergy potential: A review of existing studies and steps forward. Renewable and Sustainable Energy Reviews, 69:719-734.

Kok K, Bärlund I, Flörke M et al. (2015) European participatory scenario development: Strengthening the link between stories and models. Climatic Change, 128:187-200.

Kovats RS, Valentini R, Bouwer LM et al. (2014) Europe. In: Climate Change 2014: Impacts, Adaptation, and Vulnerability. Part B: Regional Aspects. Contribution of Working Group II to the Fifth Assessment Report of the Intergovernmental Panel on Climate Change [Barros VR et al. (eds.)]. Cambridge University Press, Cambridge, United Kingdom and New York, NY, USA, pp. 1267-1326.

Le Blanc D (2015) Towards integration at last? The Sustainable Development Goals as a network of targets. Sustainable Development, 23(3):176-187.

Liu J, Hull V, Godfray HCJ et al. (2018) Nexus approaches to global sustainable development. Nature Sustainability, 1:466-476.

Liu J, Mooney H, Hull V et al. (2015) Systems integration for global sustainability. Science, 347(6225), 1258832.

Lord S, Helfgott A, Vervoort JM (2016) Choosing diverse sets of plausible scenarios in multidimensional exploratory futures techniques. Futures, 77:11-27.

Lozano R (2008) Envisioning sustainability three-dimensionally. Journal of Cleaner Production, 16(17):1838-1846.

Maes J, Paracchini ML, Zulian G et al. (2012) Synergies and trade-offs between ecosystem service supply, biodiversity, and habitat conservation status in Europe. Biological Conservation, 155:1-12.

Mokrech M, Kebede AS, Nicholls RJ et al. (2015) An integrated approach for assessing flood impacts due to future climate and socio-economic conditions and the scope of adaptation in Europe. Climatic Change, 128:245-260.

Morales P, Sykes MT, Prentice IC et al. (2005) Comparing and evaluating process-based ecosystem model predictions of carbon and water fluxes in major European forest biomes. Global Change Biology, 11:22112233.

Mouysset L (2017) Reconciling agriculture and biodiversity in European public policies: a bio-economic perspective. Regional Environmental Change, 17(5):1421-1428.

Nilsson M, Chisholm E, Griggs D et al. (2018) Mapping interactions between the sustainable development goals: lessons learned and ways forward. Sustainability Science, 13:1489-1503.

O'Neill BC, Kriegler E, Riahi K et al. (2014) A new scenario framework for climate change research: the concept of shared socioeconomic pathways. Climatic Change, 122:387-400.

Rasul G (2016) Managing the food, water, and energy nexus for achieving the Sustainable Development Goals in South Asia. Environmental Development, 18:14-25. 
Reginster I, Rounsevell MDA (2006) Scenarios of future urban land use in Europe. Environment and Planning B: Planning and Design, 33:619-636.

Reilly M, Willenbockel D (2010) Managing uncertainty: a review of food system scenario analysis and modelling. Philos Trans R Soc Lond B Biol Sci., 365(1554):3049-3063.

Romero-Lankao P, McPhearson T, Davidson DJ (2017) The food-energy-water nexus and urban complexity. Nature Climate Change, 7:233-235.

Rounsevell MDA, Berry PM, Harrison PA (2006) Future environmental change impacts on rural land use and biodiversity: a synthesis of the ACCELERATES project. Environmental Science \& Policy, 9(2):93-100.

Sallab F, Lehsten D, Seaquist J et al. (2015) A rapid NPP meta-model for current and future climate and CO2 scenarios in Europe. Ecological Modelling, 302:29-41.

Schweizer VJ, Kurniawan JH (2016) Systematically linking qualitative elements of scenarios across levels, scales, and sectors. Environmental Modelling \& Software, 79:322-333.

Serrao-Neumann S, Crick F, Harman B et al. (2014) Improving cross-sectoral climate change adaptation for coastal settlements: Insights from South East Queensland, Australia. Regional Environmental Change, 14:489-500.

Stafford-Smith M, Griggs D, Gaffney O et al. (2017) Integration: the key to implementing the Sustainable Development Goals. Sustainability Science, 12(6):911-919.

Swart RJ, Raskin P, Robinson J (2004) The problem of the future: Sustainability science and scenario analysis. Global Environmental Change, 14(2):137-146.

UN (2013) World Economic and Social Survey 2013: Sustainable development challenges. Department of Economic and Social Affairs, United Nations Publication, E/2013/50/Rev. 1, ST/ESA/344, New York, 181pp.

UN (2015) Report of the Capacity Building Workshop and Expert Group Meeting on integrated approaches to sustainable development planning and implementation. United Nations, Department of Economic and Social Affairs: Division for Sustainable Development. 27-29 May 2015, New York, USA, 49pp.

UN (2017) Integrated approaches for Sustainable Development Goals planning: The case of Goal 6 on water and sanitation. United Nations Publication, May 2017, Bangkok, Thailand.

Vafeidis AT, Nicholls RJ, McFadden L et al. (2008) A new global coastal database for impact and vulnerability analysis to sea-level rise. Journal of Coastal Research, 24(4):917-924.

Vanham D, Leip A, Galli A et al. (2019) Environmental footprint family to address local to planetary sustainability and deliver on the SDGs. Science of the Total Environment, 693:133642.

van Vilet MTH, Vogele S, Rubbelke D (2013) Water constraints on European power supply under climate change: Impacts on electricity prices. Environmental Research Letters, 8:035010.

van Vuuren DP, Edmonds J, Kainuma M et al. (2011) The representative concentration pathways: an overview. Climatic Change, 109:5-31.

van Vuuren DP, Krieger E, O'Neill BC et al. (2014) A new scenario framework for climate change research: scenario matrix architecture. Climatic Change, 122(3):373-386.

Veerkamp CJ, Dunford RW, Harrosn PA et al. (2020) Future projections of biodiversity and ecosystem services in Europe with two integrated assessment models. Regional Environmental Change, 20:103.

Wachsmuth J (2015) Cross-sectoral integration in regional adaptation to climate change via participatory scenario development. Climatic Change, 132(3):387-400.

Wimmer F, Audsley E, Malsy M et al. (2015) Modelling the effects of cross-sectoral water allocation schemes in Europe. Climatic Change, 128:229-244.

Yamagata Y, Hanasaki N, Ito A et al. (2018) Estimating water-food-ecosystem trade-offs for the global negative emission scenario (IPCC-RCP2.6). Sustainability Science, 13:301-313. 